\title{
openheart Needs analysis of parents following sudden cardiac death in the young
}

\author{
Kristie McDonald, ${ }^{1,2}$ Louise Sharpe, ${ }^{1}$ Laura Yeates, ${ }^{2,3,4}$ Christopher Semsarian, ${ }^{2,3,4}$ \\ Jodie Ingles (D) 2,3,4
}

\begin{abstract}
- Additional material is published online only. To view please visit the journal online (http://dx.doi.org/10.1136/ openhrt-2019-001120).
\end{abstract}

To cite: McDonald K, Sharpe L, Yeates $L$, et al. Needs analysis of parents following sudden cardiac death in the young. Open Heart 2020;7:e001120. doi:10.1136/

openhrt-2019-001120

Received 1 July 2019 Revised 16 April 2020 Accepted 17 June 2020

Check for updates

(c) Author(s) (or their employer(s)) 2020. Re-use permitted under CC BY-NC. No commercial re-use. See rights and permissions. Published by BMJ.

${ }^{1}$ School of Psychology, The University of Sydney, Sydney, New South Wales, Australia ${ }^{2}$ Agnes Ginges Centre for Molecular Cardiology at Centenary Institute, The University of Sydney, Sydney, NSW, Australia

${ }^{3}$ Faculty of Medicine and Health, The University of Sydney, Sydney, New South Wales, Australia

${ }^{4}$ Department of Cardiology, Royal Prince Alfred Hospital, Sydney, NSW, Australia

Correspondence to Associate Professor Jodie Ingles; j.ingles@centenary. org.au

\begin{abstract}
Objective The sudden cardiac death (SCD) of a young person is a devastating event for any parent. Inherited heart disease is often either identified or assumed to be the cause. Few studies have explored the psychosocial impact to the surviving at-risk family members. We sought to investigate the needs of parents who have experienced the SCD of their child ( $\leq 45$ years).
\end{abstract}

Methods A quantitative needs analysis questionnaire was developed based on semistructured interviews, including one focus group and a review of relevant literature. Eligible participants were invited to participate in this crosssectional survey study.

Results There were 38 parents who completed a quantitative survey. Parents' perceived needs for information and support spanned medical, psychosocial, spiritual and financial domains. Of the support and information needs assessed, medical needs were identified as the most important domain, followed by psychosocial, spiritual and financial. Importantly, psychosocial information and support needs were reported as the most unmet need, endorsed by $54 \%$ of parents. Medical information and support needs were reported as unmet by almost one third of parents. The two most endorsed needs were 'To have the option of whether or not you would pursue genetic testing for yourself or family members' and 'To understand what happened'.

Conclusions This work demonstrates for the first time, the multifactorial needs of parents after SCD in the young. With the greatest unmet need reported as psychosocial needs, there is clear necessity to find ways of integrating psychological support in to the care of families after SCD in the young.

\section{INTRODUCTION}

The loss of a young family member is one of the most tragic events for an individual to endure, particularly when the death is sudden, unexpected, unexplained and possibly due to a heritable condition. Sudden cardiac death (SCD) in the young has an annual incidence of 1.3 per 100000 individuals in Australia and New Zealand every year. ${ }^{1}$ Inherited heart diseases account for a large majority of SCD in the young, with $40 \%$ being unascertained at postmortem examination and presumed due to inherited arrhythmia syndromes, while identifiable structural

\section{Key questions}

What is already known about this subject?

- There is currently very little known about the needs of families following a sudden cardiac death due to inherited heart diseases. We know there is significant risk of poor psychological outcomes including post-traumatic stress and prolonged grief, even years after the death, however, this is one of the first studies to formally evaluate the needs of parents during this time.

What does this study add?

- We show that medical information and support needs are ranked very highly and should always warrant careful consideration by the clinical team. Importantly, psychosocial support needs were the most unmet and our findings provide a platform for developing an approach to delivering psychosocial support interventions in this population.

How might this impact on clinical practice?

- Currently clinical and research efforts in this setting focus on clinical and genetic aspects of care. Here, we show the critical need to also focus on the psychological care needs in this population. These data will help to guide services in integrating psychological support in to their multidisciplinary clinic models.

causes such as hypertrophic cardiomyopathy, arrhythmogenic right ventricular cardiomyopathy and dilated cardiomyopathy make up approximately $16 \%$ of cases. ${ }^{1}$

First-degree relatives who have experienced the SCD of a young relative report significantly greater stress, anxiety and depression compared with the general population. ${ }^{2}$ Clinically significant symptoms of post-traumatic stress and/or prolonged grief were reported by almost half of family members, on average 6 years after the death. ${ }^{3}$ While these findings provide a brief insight into the psychological difficulties experienced by families, we are yet to understand a family's needs in the wake of the SCD of a young person.

Prior research to understand the needs of Swedish parents after the SCD of their 15-35years old child identified four needs using a qualitative approach. These included 
evidence of the death, understanding the circumstances through reconstruction, medical explanation and a sensitive approach by professionals. ${ }^{4}$ The focal goal of being understood by health professionals and themselves understanding what was going on was highlighted as important. With greater emphasis and awareness of the familial nature of SCD in the young, we sought to comprehensively understand the needs of parents whose child ( $\leq 45$ years) experienced an SCD that was thought to be due to an inherited heart disease, through development and distribution of a needs questionnaire.

\section{METHODS \\ Participants}

This was a cross-sectional survey study. Parents were recruited from the Genetic Heart Disease Clinic, Royal Prince Alfred Hospital in Sydney, Australia. We included parents whose child had died suddenly aged $\leq 45$ years with an inherited heart disease identified (or presumed to be the cause) at postmortem examination. Only cases where there was no premorbid diagnosis of an inherited heart disease were eligible. We required a sufficient level of written English skills, as self-nominated by the participant. All participants gave written informed consent prior to commencement of the interviews and questionnaire.

\section{Questionnaire development}

We developed the SCD Parental Needs Questionnaire based on one semistructured focus group and nine semistructured interviews. Thematic analysis was employed to elicit descriptive data concerning the needs that parents had experienced from their own perspective. The needs identified by parents who were interviewed and other previously designed needs assessments including in oncology, ${ }^{5}$ cardiac patients ${ }^{6}$ and parents bereaved in paediatric intensive care literature ${ }^{7}$ were reviewed to develop the content and format of the needs assessment. The questionnaire included an inventory of 45 items assessing the met and unmet needs reported by parents after SCD in the young. Forty-four needs questions were presented to each respondent. Each needs question had a dichotomous yes/no response. If 'yes' was selected, an additional two items were presented, assessing the importance of the need, measured on a three point scale (low, moderate and high) and whether the need had been met (figure 1). One of the 45 items was a screening question and only relevant to parents for whom a gene variant was identified. For this item, if parents selected 'yes' from the dichotomous response, an additional five follow-up questions were shown, in the same format as all other need questions.

In addition, demographic questions were included about the respondent (name, age and marital status), and their deceased child (gender, age at death, year of death and cause of death). Statistical analyses were conducted using SPSS V.21. Missing data were not included. Descriptive statistics were used to investigate frequency of

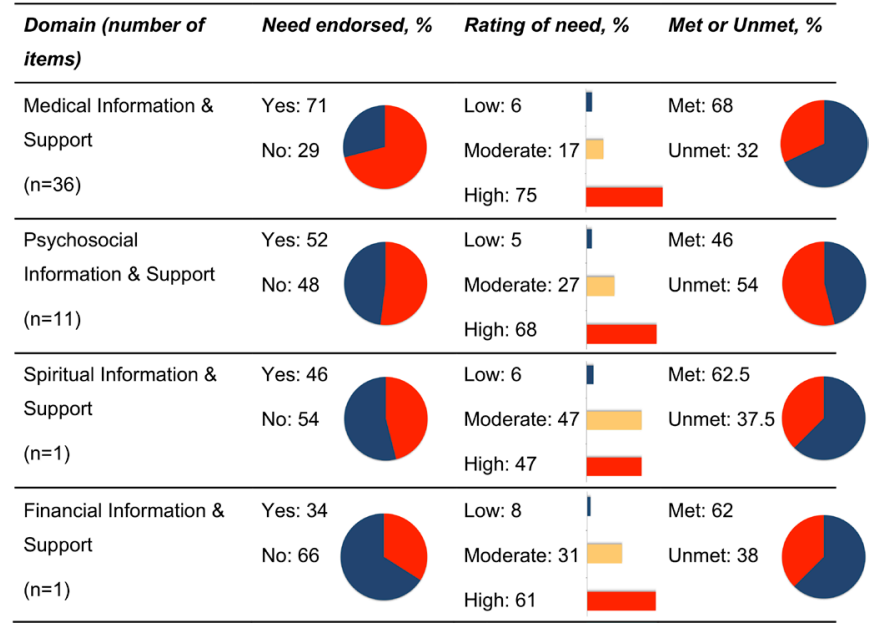

Figure 1 Summary of needs by domain.

endorsed need, the importance and whether the needs were met.

\section{SCD Parental Needs Questionnaire}

Based on the qualitative analyses, four domains of need were included in the SCD Parental Needs Questionnaire:

1. Medical information and support needs.

2. Psychosocial information and support needs.

3. Financial information and support needs.

4. Spiritual information and support needs.

\section{Medical information and support needs}

This domain encompassed parent's interactions with medical professionals at the time of and in the aftermath of the death. Professionals included paramedics, police, medical doctors, nurses and administrative support, and those involved in later care including general practitioners and cardiac specialists. Six subcategories were established: (1) information about cause of death; (2) information about heritability and consequent discussion of genetic testing; (3) information about the medical ramifications for self and family; (4) appropriate and timely referrals, for example, to cardiac specialists and/ or genetic counsellors; (5) opportunity to view the body and (6) an empathic and supportive approach by all.

\section{Psychosocial information and support needs}

This domain described psychological and social support identified by parents. Within this domain, six subcategories were established: (1) support from family; (2) support from friends; (3) support from work, including time off work and understanding of ongoing impact; (4) support from the community, including understanding by school of impact on siblings; (5) information about and access to individual therapy and (6) information about support groups.

\section{Financial information and support needs}

This domain was used to comprise monetary needs. Two subcategories were established: (1) needs relating to the young person's estate (both dealings with insurance and 


\begin{tabular}{ll}
\hline \multicolumn{1}{l}{ Table 1 Characteristics of the parents and decedent } \\
\hline Participant characteristics & $\mathbf{N}(\%)$ \\
\hline Male gender & $8(21)$ \\
\hline Mean age, years & $59 \pm 11$ \\
\hline Married/de facto & $31(82)$ \\
\hline Decedent characteristics & $\mathbf{n}(\%)$ \\
\hline Male gender & $28(74)$ \\
\hline Age at death, years & $23 \pm 10$ \\
\hline Time since death, years & \\
\hline 2-6 years & $13(34)$ \\
\hline $7-11$ years & $18(47)$ \\
\hline 12-17 years & $7(18)$ \\
Cause of death & $12(32)$ \\
\hline Known & $26(68)$ \\
\hline Unknown
\end{tabular}

bank accounts) and (2) medical costs (including clear emphasis on what appointments and tests were reimbursed by insurance).

\section{Spiritual information and support needs}

This domain encompassed all needs participants identified as relevant to: (1) their own religiosity/spirituality, (2) their family's religiosity/spirituality and (3) their child's religiosity/spirituality.

\section{RESULTS}

\section{Participants}

One hundred and twenty-four parents were directly approached, with social media recruitment used to increase participation. A total of 38 parents completed the questionnaire. Participants were approached through postal mail (19\% response rate; $24 / 124)$, telephone (12\% response rate; $3 / 25)$, email (42\% response rate; $11 / 26)$ and a Facebook advertisement $(n=2)$. Eight participants completed both the needs questionnaire and the focus group or interviews. Characteristics of the participants and the decedent are shown in table 1 . There were 8 $(21 \%)$ male participants and mean age was $59 \pm 11$ years. There were four couples. In terms of the decedent, the mean age at death was $23 \pm 10$ years and $28(74 \%)$ were male. The time since death ranged from 2 to 17 years, and $26(68 \%)$ had no clear cause of death identified at postmortem examination.

\section{Needs across the domains}

The mean of the responses across the four domains are shown in figure 1 . Of the 36 items relating to medical information and support needs, on average $71 \%$ endorsed the items as a need and $75 \%$ rated these needs as having high importance. Overall $32 \%$ reported at least one need in the medical information and support domain as unmet. There were 11 items relating to psychosocial information and support, with on average $52 \%$ reporting these as a need and of those, $68 \%$ felt the importance was high and $54 \%$ report these needs as unmet. The spiritual need was ranked as the 38th most important need, being endorsed by $46 \%$ of parents and $94 \%$ subsequently rating it as of moderate to high importance. There were $38 \%$ of parents who reported this need as unmet. The financial need was rated as the 46th most important need, being endorsed by $34 \%$ of parents; with $62 \%$ rating the importance as high and $38 \%$ reported this need as being unmet.

\section{Frequently endorsed needs}

All needs items are shown in online supplementary table 1 . Twelve needs were endorsed by $\geq 80 \%$. Of these, 11 were medical information and support needs, while one was a psychosocial information and support need. Between 63\%-93\% reported these 12 needs as being of 'high' importance. The two most endorsed needs were 'To have the option of whether or not you would pursue genetic testing for yourself or family members', with 33\% identifying this need as unmet; and 'To understand what happened", which was reported unmet by $60 \%$ of participants.

\section{Unmet needs}

Psychosocial needs were considered the most unmet. The items 'For support from your family' and 'For access to professional counselling or psychological services to deal with your bereavement' were reported as needs by $89 \%$ and $74 \%$. The most unmet needs were 'For a health professional or resources to provide you with advice for dealing with people who expected you to be 'back to normal' after your child's death' by $75 \%$; and 'For medical professionals to provide you with the opportunity to ask questions about your child's death' and 'For referral to someone to talk to who understands and has been through a similar experience' by $69 \%$. Of note, the item 'To understand the genetic cause of your child's death' was regarded as a need by $72 \%$, and $67 \%$ of participants reported this as unmet.

\section{DISCUSSION}

We show the greatest needs of families after SCD in the young are medical information and support needs, particularly relating to understanding the cause of the death. The greatest unmet needs were focused in the psychological domain, with participants reporting a need for health professionals, family and friends to have a clearer understanding of the unique clinical experience they are confronted with. As we better elucidate the clinical and genetic underpinnings of SCD in the young, our study suggests optimising the specialised multidisciplinary clinic model could potentially have an important impact on ensuring needs of surviving family members are met.

All needs in our survey were endorsed by at least $26 \%$ of participants, indicating their overall relative importance. Medical information and support needs were the most commonly endorsed overall, consistent 
with previous research highlighting that sensitive and empathic communication of the reason for the death is of paramount importance for parents. ${ }^{4}$ Understanding the cause of death was considered a key need for many, and overall was largely unmet. Given the unexpected nature of SCD in the young, whereby a large proportion of deaths remain unexplained, this is not surprising but puts even greater emphasis on the positive impact that our continuing research efforts to understand the causes of SCD in the young will have. In particular, many participants indicated access to genetic testing or understanding the genetic cause to be an important need, highlighting the importance of maintaining realistic expectations regarding the diagnostic yield of postmortem genetic testing with our families. ${ }^{9}$ At present, this is likely not greater than $15 \%$ and there is a high likelihood of uncertain genetic findings especially with increasing gene panel sizes. ${ }^{110}$

While there was a clear need for understanding the cause of death, it should be noted that these families were recruited from a specialised multidisciplinary clinic where there is a strong interest in understanding SCD in the young. It could be argued this patient group have had even greater opportunity for a cause of death to be established, access to experienced health professionals including cardiac genetic counsellors who develop a relationship with the family and provide in-depth pretest and post-test genetic counselling. The needs relating to understanding the cause of death, including genetic testing options are therefore likely underestimated in our study.

Management of families after a young SCD ideally should be performed in a specialised multidisciplinary clinic, including cardiologists, genetic counsellors and nurses to explore clinical screening and genetic testing options. There are known challenges commonly encountered when caring for families after SCD of a young relative. In particular there is a high prevalence of clinically significant symptoms of post-traumatic stress and prolonged grief. ${ }^{3}$ Reluctance to undergo clinical surveillance is also not uncommon, especially among mothers of the decedent. ${ }^{11}{ }^{12}$ Cardiac genetic counsellors and other healthcare professionals have evolved to play a key role in the management of families after SCD in the young. ${ }^{13}$ Indeed, previous research has highlighted the benefits of genetic counselling, conceptualising it as a highly circumscribed form of psychotherapy. ${ }^{14}$ Thus, increased emphasis on genetic counselling is essential to continuation of care and communication with health services. Of note, one critical role for healthcare professionals in this setting should be identification of individuals who require assessment by a clinical psychologist.

Psychosocial needs were, on average, the domain of second most importance and overall considered the most unmet. Such results shed light on the current gap in service provision, with the implication that parents are asking for, and not receiving, sufficient psychosocial support to help cope with bereavement. While previous research has both proposed the need for and demonstrated the benefits of a multidisciplinary team in the care of families with inherited cardiovascular diseases,${ }^{12}$ further research is needed to understand how to best deliver psychosocial support to SCD parents and their families. Exploring approaches such as individual counselling, for example, meaning-making narrative therapy, ${ }^{15}$ and the benefits of support groups such as affiliation and emotional support through a sense of belonging, instrumental support in the form of a safe place for discussion, practical aid in the form of informational support and normalisation and social comparison, may be beneficial. ${ }^{16}$ The role of family and friends in providing support to grieving individuals is already well described. ${ }^{17}$ Examining ways this could be further encouraged or explored with families may likewise be helpful.

When considering how to communicate information effectively to parents, educational interventions such as the GRIEV_ING death notification $\operatorname{protocol}^{18}$ may be useful within the SCD context. The GRIEV_ING mnemonic encourages professionals to 'Gather' all family members, provide 'Resources', 'Identify' yourself, your patient and the state of knowledge, 'Educate' the family about the events, 'Verify' that death has occurred, ', provide space to process and absorb information, 'Inquire' about questions, provide 'Nuts and bolts' about practical tasks (eg, organ donation and funeral services), and 'Give' access to information and support for questions that may arise later. Given the limited understanding of the cause of death, there may be limited ability to confidently and empathically provide information and support. Future research may evaluate how such an educational intervention model can be used during later stages of grieving, when cause of death is established or remains unascertained. Additionally, future research may benefit from exploring how families cope with the ambiguity surrounding SCD.

Our study was limited by the modest sample size, and despite best efforts the response rate was relatively low. The difficulty and sensitivities of recruiting this unique patient population cannot be underestimated, and the final results provide a framework for considering what needs are considered important. How these might apply more broadly, particularly to the population who do not have access to specialised clinics should be examined. In addition, the questionnaire used has not been validate.

\section{CONCLUSION}

Understanding the multifactorial needs of parents after SCD in the young is paramount for informing healthcare professionals in how to best assist and support this vulnerable population. Unmet psychosocial needs shed light on the current gap in service provision, with the implication that parents are asking for, and not receiving, sufficient psychosocial support to help cope with bereavement. Identifying how to best deliver psychosocial support to families is important, including exploring approaches 
such as individual counselling and the benefits of support groups in providing affiliation and emotional support through a sense of belonging, instrumental support in the form of a safe place for discussion, practical aid such as informational support and normalisation, may be beneficial.

Twitter Christopher Semsarian @CSHeartResearch and Jodie Ingles @ jodieingles27

Contributors All authors contributed to study design, data collection and critical revision of the manuscript. KM, JI, LY and LS contributed to data analysis. KM and $\mathrm{Jl}$ drafted the manuscript.

Funding CS is the recipient of a National Health and Medical Research Council (NHMRC) Practitioner Fellowship (\#1059156). Jl is the recipient of an NHMRC Career Development Fellowship (\#1162929). This study is funded in part by an NHMRC Project Grant (\#1059515) and National Heart Foundation Future Leader Fellowship (\#100833).

Competing interests $\mathrm{Jl}$ receives research grant support from Myokardia, Inc. Patient consent for publication Not required.

Ethics approval Royal Prince Alfred Hospital Human Research Ethics Committee approval (X13-0142 \& HREC/13RPAH/201).

Provenance and peer review Not commissioned; externally peer reviewed.

Data availability statement Data are available on reasonable request. All data relevant to the study are included in the article or uploaded as online supplementary information. Data are available in the online supplementary files and from the authors by request.

Open access This is an open access article distributed in accordance with the Creative Commons Attribution Non Commercial (CC BY-NC 4.0) license, which permits others to distribute, remix, adapt, build upon this work non-commercially, and license their derivative works on different terms, provided the original work is properly cited, appropriate credit is given, any changes made indicated, and the use is non-commercial. See: http://creativecommons.org/licenses/by-nc/4.0/.

ORCID iD

Jodie Ingles http://orcid.org/0000-0002-4846-7676

\section{REFERENCES}

1 Bagnall RD, Weintraub RG, Ingles J, et al. A prospective study of sudden cardiac death among children and young adults. $N$ Engl $J$ Med 2016;374:2441-52.
2 Yeates L, Hunt L, Saleh M, et al. Poor psychological wellbeing particularly in mothers following sudden cardiac death in the young. Eur J Cardiovasc Nurs 2013;12:484-91.

3 Ingles J, Spinks C, Yeates L, et al. Posttraumatic stress and prolonged grief after the sudden cardiac death of a young relative. JAMA Intern Med 2016;176:402-5.

4 Wisten A, Zingmark K. Supportive needs of parents confronted with sudden cardiac death--a qualitative study. Resuscitation 2007;74:68-74.

5 Azoulay E, Pochard F, Chevret S, et al. Meeting the needs of intensive care unit patient families: a multicenter study. Am J Respir Crit Care Med 2001;163:135-9.

6 Asadi-Lari M, Packham C, Gray D. Psychometric properties of a new health needs analysis tool designed for cardiac patients. Public Health 2005;119:590-8.

7 Meert KL, Templin TN, Michelson KN, et al. The bereaved parent needs assessment: a new instrument to assess the needs of parents whose children died in the pediatric intensive care unit*. Crit Care Med 2012;40:3050-7.

8 van der Werf C, Onderwater AT, van Langen IM, et al. Experiences, considerations and emotions relating to cardiogenetic evaluation in relatives of young sudden cardiac death victims. Eur J Hum Genet 2014;22:192-6.

9 Bates K, Sweeting J, Yeates L, et al. Psychological adaptation to molecular autopsy findings following sudden cardiac death in the young. Genet Med 2019;21:1452-1456.

10 Lahrouchi N, Raju H, Lodder EM, et al. Utility of post-mortem genetic testing in cases of sudden arrhythmic death syndrome. J Am Coll Cardiol 2017;69:2134-45.

11 Yeates L, Hunt L, Saleh M, et al. Poor psychological wellbeing particularly in mothers following sudden cardiac death in the young. Eur J Cardiovasc Nurs 2013;12:484-91.

12 Caleshu C, Kasparian NA, Edwards KS, et al. Interdisciplinary psychosocial care for families with inherited cardiovascular diseases. Trends Cardiovasc Med 2016;26:647-53.

13 Ingles J, James C. Psychosocial care and cardiac genetic counseling following sudden cardiac death in the young. Prog Pediatr Cardiol 2017;45:31-6.

14 Austin J, Semaka A, Hadjipavlou G. Conceptualizing genetic counseling as psychotherapy in the era of genomic medicine. $J$ Genet Couns 2014;23:903-9.

15 Neimeyer RA. Reauthoring life narratives: grief therapy as meaning reconstruction. Isr J Psychiatry Relat Sci 2001;38:171-83.

16 HMA. Health behavior and health education: theory, research and practice. 3rd edn. San Francisco, Ca: Jossey-Bass, 2002.

17 Binderman J. A Burden of Choice: The Ripple Effect: Parents' Grief and the Role of Family and Friends. In: Galst JP, Verp MS, eds. Prenatal and preimplantation diagnosis: the burden of choice. Switzerland: Springer International Publishing, 2015: 323-36.

18 Hobgood C, Harward D, Newton K, et al. The educational intervention "GRIEV_ING" improves the death notification skills of residents. Acad Emerg Med 2005;12:296-301. 